\title{
A Nexus between Malaria and Agricultural Output through the Channels of Gender, Sanitation, and Socio-Economic Status
}

\author{
Sobia Rose ${ }^{1 *}$, Muhammad Ashfaq ${ }^{1}$, Sarfraz Hassan ${ }^{1}$, Ghaffar Ali ${ }^{1,2}$ \\ ${ }^{1}$ Institute of Agricultural and Resource Economics, University of Agriculture, Faisalabad, 38000 Pakistan \\ ${ }^{2}$ Faculty of Environment and Resource Studies, Mahidol University, 73170, Nakhon, Pathom, Thailand
}

Received: 3 March 2017

Accepted: 7 May 2017

\begin{abstract}
There is not a very simple cause and effect relationship between health of farm workers, malaria, and revenue earned from agriculture. Our study was designed to understand this relationship, including all possible factors affecting agricultural output like malaria, sanitation conditions, socio economic status (SES), availability of health facilities, and the role of gender. Simultaneous equation modeling (SEM) was done to grab the underlying relationships. For assessing SES, a wealth index was created by using principle component analyses (PCA). To create the sanitation and availability of health facility indices we used multiple correspondence analysis (MCA). Results show that improvement in sanitation conditions and socio economic status have direct effects on probability of the occurrence of malaria. More investment on preventive measures and ensuring the availability of health facilities can lessen the disease burden in malaria-endemic areas that indirectly lead to the active participation of economically active members of the family. Our findings suggest that investment in women's education and farmers' training with particular focus on malaria can lead to an improvement in farmers' health that will ultimately result in quality production and increase revenue from agriculture.
\end{abstract}

Keywords: malaria, agriculture, labor, health, socio-economic status, sanitation, revenue

\section{Introduction}

Agriculture provides many benefits, including food to fulfill energy and nutritional needs and medicinal plants to treat ailments. But along with these benefits it also exerts some negative effects on human health in the form of diseases, among which malaria is the most prominent [1]. Since around 7000 B. C. with the introduction of

*e-mail: sobiarose.1464@gmail.com agriculture, malaria has remained one of the major side effects of cultivation practices on farmer health. Water development projects and irrigation schemes provide breeding sites for mosquitoes, causing an increase in malaria - especially for populations densely settled around these areas [2-3].

Farmer health requires immediate attention because healthy farmers are always more productive and therefore earn more income as compared to sick ones [4]. The yield produced by farmers suffering from malaria is about half, and they also earn less income as compared to healthy farmers [5] because good health ensures more availability 
of quality time in fields, which ultimately results in more production and income.

Family labor is one of the most important factors in agricultural production, therefore health shocks on the labor supply badly affect the benefits derived from agricultural consumption and income. More economically active members in a household fall ill due to malaria exerts a loss in family labor hours, while increased disease cost decreases agricultural investment, which further incurs an adverse effect on farm income [6]. Marginal productivity of labor causes a reduction in agricultural production due to illness, while improving health conditions of labor can enhance production and food security of households [7]. Ill health also affects performance of other household members along with some psychological costs, like grief of family members that affects labor productivity directly. Disease-avoidance cost and the cost of helping ill family members also leads to more economic losses. Consequently, the cost of ill health increases. In addition, the treatment cost of malaria also disturbs household monthly income. The present study tries to incorporate all these factors in detail by using appropriate models.

Pakistan's population is about 180 million, out of which 177 million are at risk for malaria, which makes it one of the major causes of illness in the country. The annual average of confirmed malaria cases is almost 3.5 million. The country also shares a $43.2 \%$ burden of malaria in the Eastern Mediterranean Region of the World Health Organization [8]. Reported cases of malaria are increasing each year and the relative frequency of $P$. falciparum among slide-positive malaria cases is also rising.

Despite a well-established malaria control program, there are almost 500,000 malaria infections and about 50,000 malaria-related deaths every year in Pakistan [9]. The Pakistan Directorate of Malaria includes the Muzaffargarh District among highly malaria-endemic parts of the country. It lies in the southern part of Punjab Province and is surrounded by two rivers, the Indus and the Chenab, which is why it is badly affected by floods almost every year, making it geographically suitable for mosquito production. Several other complex natural factors increase the spread of disease. High morbidity rates are always present in socially disadvantaged parts of society [10]. Poverty, lack of better sanitary conditions, and less availability of proper medical facilities serves as a catalyst in increasing the disease burden. It is difficult to control increasing temperature and changing rainfall patterns, but improvements in living conditions providing improved sanitation and health facilities can make the situation better as socio economic status (SES) differences are of great importance in public health issues [11]. Cost in the form of lost productivity and disposable income makes poor families poorer, which can eventually result in death or make people more susceptible to different infectious diseases [12]. For this purpose we targeted a detailed analysis of farmers' socio-economic conditions in Muzaffargarh. In this analysis we compared two groups of farmers: one with malarial morbidity and the other without. So the main objective of our study was to find a link between probability of malaria occurrence and revenue earned from agriculture through gender, sanitation. and SES of the farmers.

\section{Methodology}

A careful model selection procedure was adopted. The basic model for the determinants of malaria is given below, which is estimated separately with malaria as a dependent variable:

$$
\begin{gathered}
y=1, \text { if malaria is present } \\
y=0, \text { if malaria is not present }
\end{gathered}
$$

Suppose y is explained by the following relationship

$$
y=\beta x_{i}+\varepsilon_{i}
$$

...where $\varepsilon_{i}$ represents the error term

\section{Malaria Indicators trend}

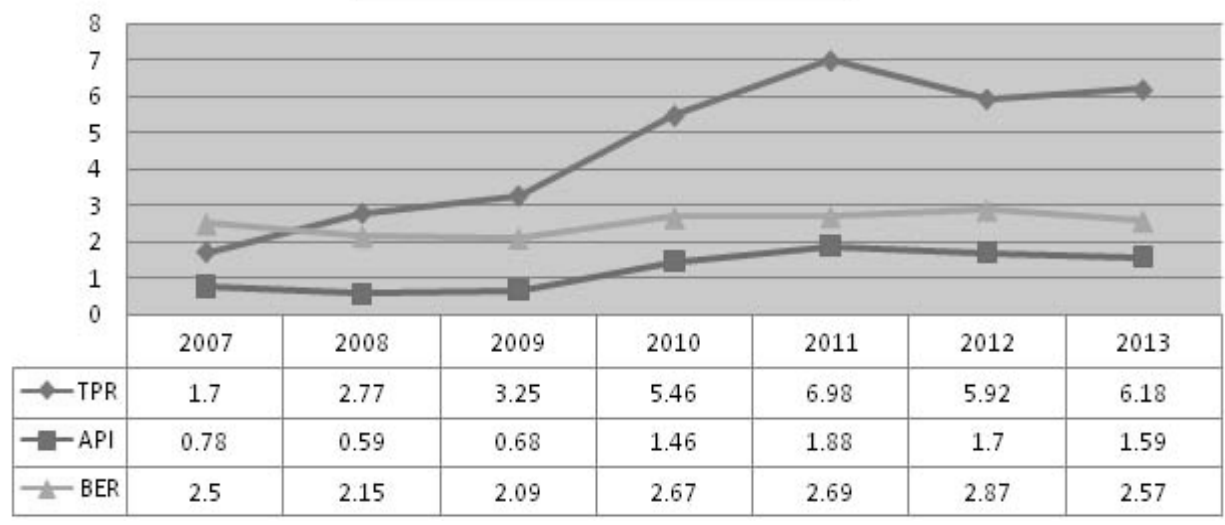

Fig. 1. Trends of malaria indicators. (GOP, 2014) 


$$
\begin{gathered}
\text { Malaria }=1 \\
=f(\text { Age,Education,Female Adults,Availibility } \\
\text { of Health Facility,Sanitation Condituon } \\
\text { Socio Economic Status,Cost of } \\
\text { Prevention,Distance from Health Facility) } \\
y=\beta_{0}+\beta_{1} \text { Age }+\beta_{2} \text { Edu }+\beta_{2} \text { FeAdult }+\beta_{3} H F \\
+\beta_{4} S C+\beta_{5} S E S+\beta_{6} \text { Distance }+B_{7} \text { COP... }
\end{gathered}
$$

Like Gwatkin [13], we replaced the missing value by mean of that variable and after estimating the basic model we estimated the system of equations. The system of equations considers the dependent variable as continuous, but in our data set the dependent variable to find the determinants of malaria was in binary form so a single equation logit model was used. If the binary dependent variable is included in the system of equations it will suffer from some shortcomings, like the error term becomes dependent on coefficients [14].

The relationship between malaria and revenue earned by farmers is complex because dual causality exists and there are also many interlinked complex pathways. While studying nested relationships, usually OLS gives inconsistent and biased estimates. So, using a system of equations gives more precise estimates of parameters [15]. This study tries to capture all those pathways by fitting a simultaneous equation model. The general form of the model is:

$$
y_{i t}=\rho\left(x_{t}, y_{t}, \gamma_{t}\right)+v_{t}
$$

...where $\mathrm{I}=1,2 \ldots \mathrm{m}$ and $\mathrm{t}=1,2 \ldots \mathrm{n}$; and is the scalar endogenous variable $\rho /=(\rho 1, \rho 2, \ldots \ldots . . \mathrm{m})$ is a true but unknown vector of $\mathrm{m}$ equation model; while $x /=\left(x_{1}\right.$, $\left.x_{2}, \ldots \ldots x_{k k}\right)$ is a k-vector of all the exogenous variables that are included in the system while $y /=\left(y_{1 t}, y_{2 t}, \ldots . . y_{m}\right)$ is the $\mathrm{m}$-vector of the set of endogenous variables included in the model and $\gamma /=\left(\gamma_{11}, \gamma_{2 t}, \ldots . . \gamma_{p t}\right)$ is a p-vector of all the unknown parameters in the structural equation and $v_{i t}=\left(v_{1 t}, v_{2 t}, \ldots . . v_{m t}\right)$ is the $\mathrm{m}$-vector of the independent random error term that is normally distributed with zero mean.

The elaborative way to write the simultaneous equation is as follows:

$$
\begin{aligned}
& Y_{1}=\gamma_{10}+\gamma_{11} X_{1}+\cdots \gamma_{1 k} X_{k}+\beta_{12} Y_{2}+\varepsilon_{1} \\
& Y_{2}=\gamma_{20}+\gamma_{22} X_{2}+\cdots \gamma_{2 k} X_{k}+\beta_{21} Y_{1}+\varepsilon_{2} \\
& Y_{3}=\gamma_{30}+\gamma_{31} X_{1}+\cdots \gamma_{3 k} X_{k}+\beta_{31} Y_{1}+\beta_{32} Y_{2}+\varepsilon_{3} \\
& ------------------- \\
& ------------------- \\
& Y_{n}=Y_{n 0}+Y_{n 1} X_{1}+\cdots \gamma_{n k} X_{k}+\beta_{n 1} Y_{1}+\beta_{n 2} Y_{2}+\varepsilon_{n}
\end{aligned}
$$

Use of the simultaneous equation model is limited because it lacks incorporating binary dependent variables [15]. In early days there were no viable alternatives to treat binary variables in a system of equations, but later on researchers suggested a two-stage approach. Probit or logit model as the first step to obtain scores of observed binary variables and then proceed with usual procedure of structural equation model as a second step by using those estimated scores as continuous probabilities [16]. We followed the same procedure considering it as appropriate to use a first equation in the framework of ordinary least square specifying logit model. So the following system of simultaneous equations was developed

$$
\begin{gathered}
S C=\beta_{0}+\beta_{1} \text { Age }+\beta_{2} \text { Edu }+\beta_{3} \text { TFLHours }+\beta_{4} \\
\text { THHMembers }+\beta_{5} \text { Malaria }+\beta_{6} \text { FA }+\beta_{7} S E S+\mu_{0} \cdots
\end{gathered}
$$

$$
\begin{aligned}
& \text { TFLHours }=\alpha_{0}+\alpha_{1} \text { DistanceHF }+\alpha_{2} \text { Age } \\
& +\alpha_{3} S C+\alpha_{4} \text { Malaria }+\alpha_{5} F A+\omega_{0} \cdots
\end{aligned}
$$

$$
\begin{gathered}
\text { THLHours }=\delta_{0}+\delta_{1} \text { Edu }+\delta_{2} \text { THHMembers } \\
+\delta_{3} \text { WDlost }+\delta_{4} S E S+\epsilon_{0} \ldots
\end{gathered}
$$

$$
\begin{gathered}
\text { Investment }=\varphi_{0}+\varphi_{1} \text { Edu }+\varphi_{2} \text { SES }+ \\
\varphi_{3} F A+\varphi_{4} \text { WDlost }+\varphi_{5} \text { TFLHours }+\varphi_{6} \\
\text { THLHours }+\varphi_{7} \text { TMalCost }+\theta_{0} \ldots
\end{gathered}
$$

$$
\begin{gathered}
\text { Revenue }=\gamma_{0}+\gamma_{1} \text { TFLHours }+\gamma_{2} \text { THLHours } \\
+\gamma_{3} \text { Malaria }+\gamma_{4} \text { SC }+\gamma_{5} \text { LogInv }+\gamma_{6} \\
\text { LogCropDamage }+\gamma_{7} \text { LogPrevCost }+\sigma_{0} \ldots
\end{gathered}
$$

...where SC represents sanitary conditions, TFLHours represents total family labor hours, and THLHours shows total hired labor hours. Cross-sectional data of 252 farmers was collected through a structured questionnaire from Muzaffargarh District.

\section{Wealth Index}

To measure households' socio-economic status all information on wealth cannot be incorporated into the model because it will result in loss of degrees of freedom. So an index was constructed. In health economics studies, constructing indices has always been used to make analysis more comprehensive and understandable. The collected information on wealth indicators was the value of assets multiplied by their numbers. Principle component analysis (PCA) was used to get a single representative value of farmers' SES, which is regarded as the most suitable technique for index construction to determine SES [17-18]. While constructing the wealth index, variables used were total land, number of cows, buffalos, goats and sheep, television, radio, computers, landline phones, mobile phones, refrigerators, and washing machines in a household. 
Table 1. Eigenvalues of the first five components (PCA).

\begin{tabular}{|l|c|c|c|c|c|}
\hline Components & 1 & 2 & 3 & 4 & 5 \\
\hline Eigenvalues & 1.99 & 1.64 & 1.08 & 1.02 & 1.02 \\
\hline
\end{tabular}

In PCA the first five components were greater than 1. The factors having eigenvalues $>1$ were kept in the analysis and all six other components were ignored according to Kaiser criterion. Some researchers only use the first component as an index for further regression analysis. Ruel and Menon [19] did a separate analysis for urban and rural households at country-level data gathered through a demographic health survey (DHS). Rather collecting data on income and consumption (which is always biased), data on household durable assets was collected. So we also collected information on the value of animals and durable assets. The first and second components explain most of the variation in data. So, an average of first and second components was used to indicate farmers' SES.

Scree-plot of eigenvalues also indicates all five components greater than 1 .

\section{Sanitation Condition and Availability of Health Facilities}

Information on sanitation could not be captured directly through a simple question so we got it through multiple indicators. Furthermore, a common index was constructed on collected information using multiple correspondence analysis (MCA). For this purpose we considered as variables water bodies near houses, were houses paved or not, were animals inside houses, animal waste management, drainage systems, kitchen gardening, debris collection near or inside houses, and use of mosquito spray. PCA can only be used where data is either in categorical form or of quantitative nature [20], whereas MCA is widely used in public health research where variables are in binary form. We separated the sanitation index from SES because combining both of these variables in the study area was not feasible, as people with good SES were not always conscious about

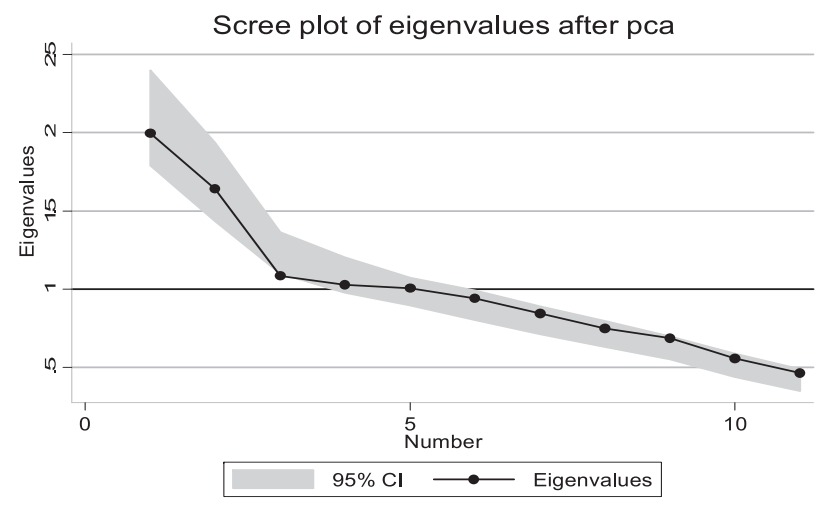

Fig. 2. Scree-plot of Eigenvalues. (Author's own calculations) sanitation conditions. Farmers usually prefer buying more agricultural inputs over installing another tap in the house or making the house paved [21].

The first dimension of the matrix was used because inertia value shows that only the first dimension is enough to explain variability in data. In our analysis, 84 percent of total inertia is explained by two dimensions, while dimension one alone explains the 81 percent of total inertia. The first step is to define a unique variable - let's call it $\mathrm{C}$. This $\mathrm{C}$ is a composite of some primary indicators computable for each population unit. A composite indicator like $\mathrm{C}$ takes the values as $\mathrm{Ci}$ (Iik, $\mathrm{K}=1, \mathrm{~K}$ ). Any composite indicator or index is a reductive variable since all the $\mathrm{K}$ variables are summarized into one. The basic technique of MCA is based on PCA, where we find a linear combination of uncorrelated variables called latent variables, and these latent variables are the components [22].

\section{Results and Discussion}

The results of the model explain complex interlinkages of different factors affecting the health of farmers. After finding some important determinants of malaria it was determined how disease affects labor availability. Through its effects on family labor, hired labor, and agricultural investment, it was found that malaria significantly affects revenue earned from agriculture.

\section{Determinant of Malaria}

The effects of ill health due to malaria on farm labor, investment, and revenue earned from agriculture was modeled simultaneously.

Education creates awareness that eventually results in better health conditions, and our results also indicate that the probability of malaria decreases as education increases [23-24]. In addition, education age is also a symbol of maturity and experience that reflects the probability of malaria's decrease as age increases [25].

The number of female adults in a household shows the distribution of domestic resources [26]. With more women in a family, they should have more control of income and other resources [27]. But in rural Pakistan females are not much empowered and usually get married at early ages, and mostly pregnant females - due to the lack of adequate health facilities - become victims of malaria. Furthermore, they are also involved in housecleaning activities and managing livestock, which makes them easy targets of the disease. This is why the probability of malaria increases with more adult females in a household in the study area. The health facility index 
Table 2. Determinant of malaria (Equation 1).

\begin{tabular}{|c|c|c|c|c|}
\hline Variable Names & Variable description & Coefficient & Standard error & P-Values \\
\hline Constant & Constant & $\mathbf{0 . 7 8 4 3}$ & & 0.0210 \\
\hline Age & Age (years) & -0.0481 & 0.0347 & 0.661 \\
\hline Edu & Education (years) & -0.0152 & 0.2641 & $0.005^{* *}$ \\
\hline FeAdult & Female adults (number) & 0.7352 & 0.2059 & $0.032^{*}$ \\
\hline HF & Health facility (number) & 0.4421 & 0.2091 & $0.000^{* * *}$ \\
\hline SC & Sanitary conditions (index) & -1.5827 & 0.1307 & $0.069^{*}$ \\
\hline SES & SES (index) & -0.2373 & 0.0713 & $0.057^{*}$ \\
\hline Distance & Availability of the health facility & 0.1356 & 0.1406 & $0.025^{*}$ \\
\hline COP & Cost of prevention (rupees) & -0.3147 & & \\
\hline
\end{tabular}

reveals a surprising finding that probability of malaria increases with more health facilities. This result was unexpected because increased health facilities should cause a reduction in malaria. In this case we observed greater availability of health facilities, but due to lack of proper treatment the number of cases increased, which shows that access to facilities exerts no effect on the spread of the disease [28]. This makes it clear that the mere existence of the health facility cannot minimize the disease burden unless and until its quality is improved. Distance from a health facility also plays an important role in controlling malaria because as distance increases the probability of malaria also increases [29-30]. We observed the same in the study area because farmers do not visit the health facilities regularly during their illness but instead go to hospital once and then prefer selfmedication [31-32].

A good socio economic status is generally associated with reduction in malaria [11] because the availability of more resources enhances adaptability and the capacity to undertake preventive measures [33-35] like using mosquito repellents, insecticide-treated nets, and other precautionary measures to avoid the disease. In severe malaria transmission areas the relationship between malaria and socio economic status is bidirectional [36]. Findings of this research also confirm that the probability of malaria decreases with farmers' improved SES.

Scaling up prevention activities has led to averting 0.8 million malaria-related deaths in children [37]. In the study area, expenditures on malaria prevention were found to be causing a significant decrease in probability of the disease, although these prevention expenditures indirectly put a financial burden on households [26]. Family size also matters, as results show that larger households are associated with a significant increase in malaria prevalence.

\section{Simultaneous Equation Model (SEM)}

After estimating factors affecting the probability of malaria, we estimated SEM.

\section{Effects of Sanitary Conditions}

Improving the sanitization infrastructure and drainage facilities always helps lower incidences of malaria, especially in rural areas where impoverished living conditions of farm workers help sustain malaria transmission [38]. Equation 2 of SEM explains the effect of labor hours and gender on sanitatary conditions. The results of the first equation show that although malaria is not a leading cause of morbidity, it is a common and widespread illness in the study area [39]. Several factors contribute to the spread of malaria, but lack of proper sanitation and close proximity to water bodies are two of the most observed causes. SEM indicated sanitary conditions as one of the important determinants of malaria that are directly related to disease burden. Findings show significant improvement in sanitary conditions of a household as a respondent's age increases because people become more conscious of cleanliness and hygiene.

Total family labor hours is the sum of hours spent on a farm during the land preparation, field management, and harvest stages. Spending more hours in agricultural activities causes significant damage to sanitary conditions of households because they are unable to invest reasonable time in improving sanitation, and people in rural areas also prefer to spend more time in agricultural as compared to cleaning activities. There is a bidirectional relationship between household sanitation and malaria prevalence. A cost-benefit analysis by WHO showed that improve-ment in water and sanitation can bring a substantial increase in economic growth through improved health. Only the investment of US\$1 million would bring the economic returns of US\$3 million to US\$34 million depending on different regions. It will also reduce the health costs that will cause a gain in global value of working days by $\$ 750$ million US annually as a result of less illness. It will also generate more savings for households through reduced cost and avoid loss of time [40-41]. This will enable individuals to be engaged in more productive activities. The indicators in the index are plausible reasons behind increasing the spread of malaria in the study area, and 
Table 3. Results of simultaneous equation model.

\begin{tabular}{|c|c|c|c|c|}
\hline \multicolumn{5}{|c|}{$\begin{array}{c}\text { (Equation 2) } \\
\text { Effects of Sanitary Conditions } \\
\text { Dependent Variable = Sanitary Conditions (SC) }\end{array}$} \\
\hline \multirow[t]{2}{*}{ Variable Names } & Variable detail & Coefficient & Standard error & P-Values \\
\hline & Constant & 4.7062 & & \\
\hline Age & Age & 0.0206 & 0.0074 & 0.005 \\
\hline Edu & Education & 0.0139 & 0.0098 & 0.151 \\
\hline TFL Hours & Total family labor hours & -0.3391 & 0.0447 & 0.000 \\
\hline THH Members & Total household members & -0.0622 & 0.0198 & 0.002 \\
\hline Malaria & Malaria & 0.7819 & 0.1042 & 0.000 \\
\hline FA & Female adults & -0.1089 & 0.1069 & 0.308 \\
\hline SES & SES & 0.5103 & 0.1163 & 0.000 \\
\hline \multicolumn{5}{|c|}{$\begin{array}{r}\text { (Equation 3) } \\
\text { Effect of Ill Health on Family Lab } \\
\text { Dependent Variable = Total Family Labor } \mathrm{H}\end{array}$} \\
\hline & Constant & -0.3927 & & \\
\hline Distance HF & Average distance from health facility & -0.6399 & 0.2029 & 0.002 \\
\hline Age & Age & 0.2578 & 0.0576 & 0.000 \\
\hline Edu & Education & -0.0159 & 0.0719 & 0.824 \\
\hline SC & Sanitation condition & -8.9169 & 1.6105 & 0.000 \\
\hline Malaria & Malaria & 28.0013 & 5.3595 & 0.000 \\
\hline FA & Female adults & -4.0812 & 0.7548 & 0.000 \\
\hline \multicolumn{5}{|c|}{$\begin{array}{c}\text { (Equation 4) } \\
\text { Effects of Ill Health on Hired Labor Hours } \\
\text { Dependent Variable = Total Hired Labor Hours (THLHours) }\end{array}$} \\
\hline Dependent Variable $=$ THL Hours & Constant & 25.15814 & & \\
\hline Edu & Education & 0.1270 & 0.0429 & 0.003 \\
\hline THH Members & Total household members & 0.0061 & 0.0668 & 0.927 \\
\hline WD Lost & Total working days lost due to illness & 0.2415 & 0.1096 & 0.028 \\
\hline SES & Wealth & -0.3443 & 0.1572 & 0.029 \\
\hline \multicolumn{5}{|c|}{$\begin{array}{c}\text { (Equation 5) } \\
\text { Effects of Malaria Cost on Farm Investment } \\
\text { Dependent Variable = Investment }\end{array}$} \\
\hline & Constant & 10.5419 & & \\
\hline Edu & Education & 0.0047 & 0.0021 & 0.028 \\
\hline SES & Wealth & 0.0889 & 0.0254 & 0.000 \\
\hline FA & Female adult & -0.0307 & 0.0134 & 0.022 \\
\hline WD Lost & $\begin{array}{c}\text { Loss in total working days by family } \\
\text { labor }\end{array}$ & 0.0095 & 0.0012 & 0.432 \\
\hline TFL Hours & Total family labor hours & 0.0108 & 0.0044 & 0.014 \\
\hline THL Hours & Total hired labor hours & -0.0079 & 0.0098 & 0.421 \\
\hline TMalCost & Malaria cost & 0.0682 & 0.0324 & 0.035 \\
\hline
\end{tabular}


Table 3. Continued.

\begin{tabular}{|c|c|c|c|c|}
\hline \multicolumn{5}{|c|}{$\begin{array}{c}\text { Equation 6) } \\
\text { Factors affecting Revenue from Agriculture } \\
\text { Dependent Variable = Revenue }\end{array}$} \\
\hline & Constant & 6.6376 & & 0.483 \\
\hline TFL Hours & Total family labor hours & -0.0031 & 0.0044 & 0.120 \\
\hline THL Hours & Total hired labor hours & 0.0267 & 0.0172 & 0.059 \\
\hline Malaria & Malaria & -0.2064 & 0.1093 & 0.073 \\
\hline SC & Sanitary conditions & 0.0696 & 0.0389 & 0.000 \\
\hline LogInv & Log of total investment & 0.5762 & 0.0881 & 0.165 \\
\hline LogCropDamage & Log of total crop damage & 0.0044 & 0.0032 & 0.000 \\
\hline LogPrevCost & Log of malaria prevention cost & 0.0146 & 0.0041 & \\
\hline
\end{tabular}

this shows that SEM improvement can lead to better sanitation and improved living conditions [42], which will further reduce incidences of malaria.

\section{Effect of Ill Health on \\ Family Labor Hours}

The dependent variable in Equation 3 is total family labor hours, which is the average daily time spent by all economically active family members on farming activities. Although information was collected by splitting total farming activity into three stages (land preparation, field management, and harvesting), analysis of all three stages separately was not giving meaningful coefficients. So all information was combined and a variable showing total time spent by the family members on farming activities in one day as an average of all three stages was generated. In case a person falls ill due to malaria then one or two members engage in seeking medical aid, which exerts a significantly negative effect on time spent on farming activities [43]. Family labor hours significantly decrease (-0.6399). Because they have to look after the ill family members and seek medical treatment, they need to travel long distances, which not only increases the transportation cost, but the time spent on farm activities also decreases, leading to the need to hire more labor that further depends on a household's SES [44].

Results show age as an important determinant of time spent on farming activities. As age increases, farmers spend more time on farming activities, which increases family labor hours $(0.2578)$. Sanitation conditions are another very important factor determining time spent in fields by family members. A highly significant and negative relationship was not according to a priori expectations. A negative sign might show the absence of a proper waste management schedule from municipal administration so that people, especially women in a household, spend more time in clearing ditches and handling animal waste. Furthermore, unpaved houses take more time to be cleaned, and if there are animals inside the house, any clogged ditch near house, or there is not a proper sewerage arrangement then it takes more time to be spent at home - especially by adult females who are also economically active in the family [45-46]. This is why the coefficient for female adults is also negative. Time spent on farm activities significantly decreases (-4.0812) with one more female member in a household. Malaria affects women's health, which increase disease cost and absenteeism from the fields. In such cases families need to hire more labor, which ultimately results in increased cost and decreased revenue. As more family members fall ill due to malaria the total time spent on agricultural activities significantly increases (28.0013).

\section{Effects of Ill Health on Hired Labor Hours}

When a family member's education level increases they might rather seek a white-collar job than work in the fields, resulting in a reduction in family labor and the need to hire help. Findings reveal losses in total working hours by family members affect hired labor hours in the study area [4-44]. Working days are lost if a family member falls ill (male or female) among economically active members. Firstly, when the household head is suffering from malaria and some other family members have to take time off to provide care, or when a child or elderly person suffers from malaria and people working on the farm need to take care of that family member full time so in this equation total days lost in both situations were combined. Findings reveal a significant positive relationship between total working days lost and hired labor hours [47].

\section{Effects of Malaria Cost on Farm Investment}

Variable investment is the sum of value of tools, seeds, and chemicals for the land preparation, field management, and harvesting stages. The effect of malaria illness on agricultural investment is examined by combining investments on all three stages of crop 
production. Illness affects agricultural investment due to additional expenditures on disease cure that eventually deplete investment capital. This equation shows the effect of different variables and SES on their investment on agriculture in one season. Results point to increased investment $(0.47 \%)$ with more education, although it is a significant but very small effect. While households with good SES have a positive and highly significant effect (8.89 \%) on agriculture, agricultural investment considerably decreases by 3 percent with one more economically active female adults in the family. This decreased investment may occur due to high malaria prevalence in females because they can catch malaria while performing housecleaning activities and fieldwork. Moreover, rural women have high fertility rates, which results in the "quantity-quality trade-off," and women are mostly left for child bearing, and then taking care of children reduces their role in economic activities [12]. More investment in women's health and education can help them participate in agricultural activities and make them more productive individuals [48].

Although labor days off significantly affect investment decisions, total losses in working days do not have a significant effect on agricultural investment in the study area because family labor is always substituted with hired labor and hired labor is usually paid in kind. So labor days off do not significantly affect investment. As family labor hours increase, agricultural investment increases by 1 percent. The cost of prevention includes cost on adaptive measure to avoid malaria, dietary expenses on ill family members, medication cost, transportation cost, and other related costs that significantly affect the agricultural investment (6.8 percent) [49].

\section{Factors Affecting Revenue from Agriculture}

Illness due to malaria always causes a reduction in worker productivity and consequently reduces agricultural output [4]. So this equation estimates the effect of ill health on revenue earned from agriculture. Agricultural revenue decreases with more ill family members (20\%) and sanitation conditions (6\%). Access to a medical facility and the provision of a clean environment can also decrease the spread of the disease, which in turn will ultimately lead to increases in investment and revenue earned from agricultural output. Results highlight the huge impact of total investment on agricultural revenue. Increases in total investment lead to increases in revenue (57\%). Similarly, investment on malaria prevention also increases revenue (1.4\%).

\section{Conclusion and Policy Implications}

Engaging in farming activities increases the spread of disease. This does not mean practicing agriculture should be abandoned, but counterfactual scenarios should be developed to lessen the disease burden.
Sanitatary conditions and farmers' SES directly affect the probability of malaria in the study area. Therefore, controlling community-level transmissions of malaria can be done by improving sanitary conditions. Furthermore, this study also identifies the fact that more investment on preventive measures and making sure of the availability of health care facilities can lessen the disease burden especially in malaria-endemic areas, which will indirectly lead to the active participation of economically active family members.

Significant effects of malaria on revenue from agriculture were seen. The study suggests that investing in farmer training with a particular focus on malaria can improve farmers' health, which will ultimately result in more production and higher revenue. So there should be a broad spectrum approach focusing on both fundamental and proximal causes to combat malaria. Future malaria control measures should give special consideration to farmer health, and anti-malaria measures should be directed toward the provision of education in general and women's education in particular, and health facilities within reasonable distance along with quality equipment to diagnose and treat the disease with due consideration to a farmer's SES.

This study also suggests that no single measure is sufficient to control malaria, so future anti-malaria campaigns need to adopt diverse strategies in local health services and interrelated agricultural practices. Moreover, a certain threshold socioeconomic development, health services infrastructure, and educational level may have to be reached for the successful application and maintenance of direct anti-malaria measures. A well-managed farming activity is required with no negative impact on farmers' health, which further improves environmental sustainability and which is called disease prevention with "reasonable" actions.

\section{Acknowledgements}

The research was not funded from any funding agency. However, special thanks to the reviewers for their valuable comments to bring this article in a better form.

\section{List of Abbreviations}

- SES: socio-economic status

- SEM: simultaneous equation model

- PCA: principle component analysis

- MCA: multiple correspondence analysis

\section{References}

1. ARON J.L., PATZ J. Ecosystem change and public health: a global perspective. JHU Press, 2001.

2. KIBRET S., MCCARTNEY M., LAUTZE J., JAYASINGHE G. Malaria transmission in the vicinity 
of impounded water: Evidence from the Koka Reservoir, Ethiopia 132, IWMI, 2009.

3. ASENSO-OKYERE K., CHIANG C., ANDAM K. $\mathrm{S}$. Interactions between health and farm-labor productivity. Intl Food Policy Res Inst, 2011.

4. ASENSO-OKYERE K., ASANTE F.A., TAREKEGN J., ANDAM K.S. The linkages between agriculture and malaria: Issues for policy, research, and capacity strengthening. Intl Food Policy Res Inst, 2009.

5. GIRARDIN O., DAO D., KOUDOU B.G., ESSÉ C., CISSÉ G., YAO T., N’GORAN E.K., TSCHANNEN A.B., BORDMANN G., LEHMANN B., NSABIMANA C. Opportunities and limiting factors of intensive vegetable farming in malaria endemic Côte d'Ivoire. Acta Tropica. 89 (2), 109, 2004.

6. KILLEEN G.F., FILLINGER U., KICHE I., GOUAGNA L.C., KNOLS B.G. Eradication of Anopheles gambiae from Brazil: lessons for malaria control in Africa?. The Lancet infectious diseases. 2 (10), 618, 2002.

7. LAROCHELlE C., DALTON T.J. Transient Health Shocks and Agricultural Labor Demand in Rice-producing Households in Mali. Available at SSRN 2017733, 2005.

8. GOP. Government of Pakistan, Ministry of Finance, Pakistan Economic Survey, 2013.

9. KHATTAK A.A., VENKATESAN M., NADEEM M.F., SATTI H.S., YAQOOB A., STRAUSS K., KHATOON L., MALIK S.A., PLOWE C.V. Prevalence and distribution of human Plasmodium infection in Pakistan. Malaria journal. 12 (1), 297, 2013.

10. ODOLINI S., GAUTRET P., KAIN K.C., SMITH K., LEDER K., JENSENIUS M., COYLE C.M., CASTELLI F., MATTEELLI A. Imported Plasmodium vivax malaria ex Pakistan. Journal of travel medicine. 21 (5), 314, 2014.

11. DICKINSON K.L., RANDELL H.F., KRAMER R.A., SHAYO E.H. Socio-economic status and malaria-related outcomes in Mvomero District, Tanzania. Global public health. 7 (4), 384, 2012.

12. SACHS J., MALANEY P. The economic and social burden of malaria. Nature. 415 (6872), 680, 2002.

13. GWATKIN D.R., RUSTEIN S., JOHNSON K., SULIMAN E., WAGSTAFF A., AMOUZOU A. Socio-economic differences in Brazil. Washington, DC: HNP/Poverty Thematic Group of the World Bank, 2000.

14. GATES S., GLEDITSCH N.P., NEUMAYER E. Environmental commitment, democracy, and inequality. World Development Report, 2003.

15. GREENE W.H. Econometric Analysis. Fifth Edition, Prentice Hall Publishers, New York, U. S. A., 2003.

16. ANGRIST J.D. Estimation of limited dependent variable models with dummy endogenous regressors. Journal of business \& economic statistics. 19 (1), 2, 2012.

17. FILMER D., PRITCHETT L.H. Estimating wealth effects without expenditure data - or tears: an application to educational enrollments in states of India. Demography. 38 (1), 115, 2001.

18. KOLENIKOV S., ANGELES G. Socioeconomic status measurement with discrete proxy variables: Is principal component analysis a reliable answer?. Review of Income and Wealth. 55 (1), 128, 2009.
19. RUEL M.T., MENON P. Creating a child feeding index using the demographic and health surveys: an example from Latin America. Washington, DC: International Food Policy Research Institute, 2002.

20. DE LEEUW J. Nonlinear principal component analysis and related techniques. Department of Statistics, UCLA. 2011.

21. BOOYSEN F., VAN DER BERG S., BURGER R., VON MALTITZ M., DU RAND G. Using an asset index to assess trends in poverty in seven Sub-Saharan African countries. World Development. 36 (6), 1113, 2008.

22. ASSELIN L.M., ANH V.T. Multidimensional poverty and multiple correspondence analysis. In Quantitative approaches to multidimensional poverty measurement. Palgrave Macmillan UK. 80, 2008.

23. ANDERSON J.O., THUNDIYIL J.G., STOLBACH A. Clearing the air: a review of the effects of particulate matter air pollution on human health. Journal of Medical Toxicology, 8 (2), 166, 2012.

24. FRENK J., CHEN L., BHUTTA Z.A., COHEN J., CRISP N., EVANS T., FINEBERG, H., GARCIA, P., KE Y., KELLEY P., KISTNASAMY B. Health professionals for a new century: transforming education to strengthen health systems in an interdependent world. The lancet, 376 (9756), 1923, 2010.

25. GIHA H.A., ROSTHOJ S., DODOO D., HVIID L., SATTI G.M., SCHEIKE T., ARNOT D.E., THEANDER T.G. The epidemiology of febrile malaria episodes in an area of unstable and seasonal transmission. Transactions of the Royal Society of Tropical Medicine and Hygiene. 94 (6), 645, 2000.

26. SIRI J.G. Independent associations of maternal education and household wealth with malaria risk in children. Ecol Soc. 19 (1), 33, 2014.

27. MEINZEN-DICK R., BEHRMAN J., MENON P., QUISUMBING A. Gender: A key dimension linking agricultural programs to improved nutrition and health. Reshaping agriculture for nutrition and health, 135, 2012.

28. PETTI C.A., POLAGE C.R., QUINN T.C., RONALD A.R., SANDE M.A. Laboratory medicine in Africa: a barrier to effective health care. Clinical Infectious Diseases, 42 (3), 377, 2006.

29. BISANZIO D., MUTUKU F., LABEAUD A.D., MUNGAI P.L., MUINDE J., BUSAIDY H., MUKOKO D., KING C.H., KITRON U. Use of prospective hospital surveillance data to define spatiotemporal heterogeneity of malaria risk in coastal Kenya. Malaria journal, 14 (1), 482, 2015.

30. CHATURVEDI H.K., MAHANTA J., BAJPAI R.C., PANDEY A. Risk of malaria among febrile patients: retrospective analysis of a hospital-based study in an endemic area of northeast India. International health, 6 (2), 144, 2014.

31. VAN DER HOEK W., KONRADSEN F., AMERASINGHE P.H., PERERA D., PIYARATNE M.K., AMERASINGHE F.P. Towards a risk map of malaria for Sri Lanka: the importance of house location relative to vector breeding sites. International Journal of Epidemiology. 32 (2), 280, 2003.

32. THWING J.I., MIHIGO J., FERNANDES A.P., SAUTE F., FERREIRA C., FORTES F., DE OLIVEIRA A.M., NEWMAN R.D. How much malaria occurs in urban 
Luanda, Angola? A health facility-based assessment. The American journal of tropical medicine and hygiene. 80 (3), 487, 2009.

33. MCELROY B., WISEMAN V., MATOVU F., MWENGEE W. Malaria prevention in north-eastern Tanzania: patterns of expenditure and determinants of demand at the household level. Malaria Journal. 8 (1), 95, 2009.

34. SATO A. Does socio-economic status explain use of modern and traditional health care services?. Social Science \& Medicine. 75 (8), 1450, 2012.

35. MARGAI F.M., MINAH J.B. Malaria Risk Profiles, Treatment Seeking Practices and Disease Intervention Efforts in Poor Communities: A Case Study in Sierra Leone. Geographies of Health and Development. 11, 2016.

36. SOMI M.F., BUTLER J.R., VAHID F., NJAU J., KACHUR S.P., ABDULLA S. Is there evidence for dual causation between malaria and socioeconomic status? Findings from rural Tanzania. The American journal of tropical medicine and hygiene. 77 (6), 1020, 2007.

37. EISELE T.P., LARSEN D.A., WALKER N., CIBULSKIS R.E., YUKICH J.O., ZIKUSOOKA C.M., STEKETEE R.W. Estimates of child deaths prevented from malaria prevention scale-up in Africa 2001-2010. Malaria journal. 11 (1), 93, 2012.

38. CARTER E.D. Malaria, landscape, and society in northwest Argentina in the early twentieth century. Journal of Latin American Geography. 7-38, 2008.

39. RANA S.M., KHAN E.A., YAQOOB A., LATIF A.A., ABBASI M.M. Susceptibility and irritability of adult forms of main malaria vectors against insecticides used in the indoor residual sprays in Muzaffargarh district, Pakistan: a field survey. Journal of medical entomology. 51 (2), 387, 2014.

40. BARTRAM J., LEWIS K., LENTON R., WRIGHT A. Focusing on improved water and sanitation for health. The Lancet. 365 (9461), 810, 2005.
41. GANI B.A., CHIROMA A., GANA B.A. Women and solid waste segregation in Bauchi Nigeria. Women. 2 (8) 2012.

42. STRATTON L., O’NEILL M.S., KRUK M.E., BELL M.L. The persistent problem of malaria: Addressing the fundamental causes of a global killer. Social science \& medicine. 67 (5), 854, 2008.

43. RICCI F. Social implications of malaria and their relationships with poverty. Mediterranean journal of hematology and infectious diseases. 4 (1), 2012.

44. ULIMWENGU J. Farmers' health and agricultural productivity in rural Ethiopia. African Journal of Agricultural and Resource Economics. 3 (2), 83, 2009.

45. CORBURN J., HILDEBRAND C. Slum sanitation and the social determinants of women's health in Nairobi, Kenya. Journal of environmental and public health, 2015.

46. LIM S.S., VOS T., FLAXMAN A.D., DANAEI G., SHIBUYA K., ADAIR-ROHANI H., ALMAZROA M.A., AMANN M., ANDERSON H.R., ANDREWS K.G., ARYEE M. A comparative risk assessment of burden of disease and injury attributable to 67 risk factors and risk factor clusters in 21 regions, 1990-2010: a systematic analysis for the Global Burden of Disease Study 2010. The lancet, 380 (9859), 2224, 2013.

47. BADIANE O., ULIMWENGU J. Malaria incidence and agricultural efficiency in Uganda. Agricultural Economics. 44 (1), 15, 2013.

48. SCHULTZ T.P. Why governments should invest more to educate girls. World Development. 30 (2) 207, 2002.

49. CHUMA J., OKUNGU V., MOLYNEUX C. The economic costs of malaria in four Kenyan districts: do household costs differ by disease endemicity?. Malaria Journal. 9 (1), 149. 2010. 